\title{
Testing Explanatory Power of Two Behavioral Models for Price Continuation
}

\author{
Hsiao-Peng $\mathrm{Fu}^{1}$ \\ ${ }^{1}$ Department of Finance, Providence University, Taiwan, R.O.C. \\ Correspondence: Hsiao-Peng Fu, Department of Finance, Providence University, 200, Section 7, Taiwan Boulevard \\ Road, Shalu District, Taichung 43301, Taiwan, R.O.C. Tel: 8864-2632-8001 Ext. 13614.
}

Received: March 1, 2016

Accepted: March 7, 2016

Online Published: March 21, 2016

doi:10.5430/ijfr.v7n2p93

URL: http://dx.doi.org/10.5430/ijfr.v7n2p93

\begin{abstract}
The overconfidence and self-attribution model developed by Daniel, Hirshleifer and Subrahmanyam (1998) forecasts a stronger price continuation for low book-to-market stocks. Besides, Hong and Stein's (1999) sluggish information spreading model predicts a higher price continuation for small firms. This study provides evidence that neither predictions can hold in the Taiwanese stock market, inconsistent with the strong confirmation of US evidence. The discrepancy of results in the two markets implies that existence of price continuation might be a global phenomenon, yet the underlying sources may be market specific.
\end{abstract}

Keywords: price momentum, seasonality, overreaction, emerging markets

\section{Introduction}

As Jegadeesh and Titman (1993) reveal the price continuation phenomenon, many researchers followed their steps, conducting immense empirical tests and developing behavioral models to explain the phenomenon obviously contradicting to efficient market hypothesis. The price contimuation has been discovered in most developed financial markets, yet not so prevalently found among emerging markets. Rouwenhorst (1998), for instance, confirm the strong intermediate-term price momentum effects in arbitrage portfolios constructed either across 12 European stock markets or within each market. Liu et al. (1999) present significant evidence for U.K., and so do Schiereck et al. (1999) for Germany. Chan et al. (2000) found short-term strong results for portfolios consisting of international stock market indices of 23 markets world widely. Grundy and Martin (2001) find the existence of momentum effects in U.S. as early as since 1926. On the other hand, Rouwenhorst (1999), for example, find momentum profits in 20 emerging markets as a whole as well as in 8 individual markets. Nevertheless, momentum effects are not obvious in the remaining 12 individual markets. With regards the Asian markets, price momentum effects are normally weak, occasionally strong in certain markets over certain time periods or in joint sample of several countries. For example, Chui et al. (2003) study stock return behaviours of eight Asian countries, finding significant price momentum effects for arbitrage portfolios constructed on securities from all countries in the sample excluding Japan, and also for portfolios ranked solely on stocks from Hong Kong over years between 1976 and 2000 as well as between 1976 and 1997, but not between 1997 and 2000. In contrast, the other seven Asian countries in their sample primarily do not exhibit strong momentum profits. Likely, both Hameed and Yuanto (2002) and Griffin et al. (2005) provide weak evidence of price momentum for respective six and ten Asian counties (including Japan) in terms of individual countries or the whole area on average. Kang et al. (2002) find significant momentum profits in China.

Like other Asisn markets mentioned previously, no evident momentum profits are uncovered in Taiwan (e.g., Rouwenhorst, 1999; Chen, 2000; Hameed and Yuanto, 2002; Chui et al., 2003; Griffin et al., 2005). Fu and Wood (2010), however, report that considerable momentum profits are detected over the calendar months of April to August in the market for various combinations of mid-term rank and test periods. Furthermore, the results are robust in sub-samples. Most importantly, they also uncover a role of overreaction in introducing the seasonal price continuation.

This paper extends findings of $\mathrm{Fu}$ and Wood (2010) by testing explanatory power of two behavioral models involving overreaction so as to investigate which model provide a better capacity of interpreting the seasonal Taiwanese momentum. The two behavioral models are: the overconfidence and self-attribution model argued by Daniel, Hirshleifer and Subrahmanyam (1998) (henceforth as DHS), and the gradual-information-diffusion model 
proposed by Hong and Stein (1999). As a pure overreaction theory, DHS employ cognitive concepts of overconfidence and self-attribution to profile a process of short-term overreaction to private information together with long-term correction. Firstly they distinguish two different types of market participants: the investors who receive information and those who do not. Momentum returns are mainly attributable to the behaviours of overconfident investors who show two biases-overconfidence and self-attribution. Overconfidence indicates putting too much weight in private information but too little in public information. Self-attribution refers to update confidence in a way that confidence is accelerated when outcomes of the previous action confirm the previous private information, but confidence is only accentuated moderately when outcomes do not confirm prior private information. That is, investors biasly attribute disconfirmation to outside noises. Accordingly, on average, overconfidence is increased across time, inducing mid-term momentum effects. In the long run, however, the mis-pricing is eventually corrected when opposite sign public information is considerably enough to overwhelm private information. On the other hand, HS assert that a stock market consists of two distinct types of bounded rational investors: news watchers and momentum traders. News watchers are those investors whose investment decisions depend only on accessible firm-specific private information, whereas momentum traders are investors who solely rely on historical stock prices. Under the important assumption that firm-specific information disseminates slowly, newswatchers under-react at an aggregate level in short-term to mid-term. At the same time, when momentum traders detect momentum in prices, they enter the market, intend to exploit profits from under-reaction behaviors of newswatchers, and follow price momentum dynamics all the way to the overreaction stage. The key assumption of the slow spreading of private information is empirically confirmed by Hong, Lim, and Stein (2000), who show that momentum is most evident for firms with low analyst coverage.

In this paper, I use two firm characteristics to test the models. Firstly, Daniel and Titman (1999) find that in the U.S. stocks with low book-to-market securities exhibit stronger momentum effects than high book-to-market securities. They attribute this phenomenon to the theory of DHS. That is, investors are more likely to overestimate intrinsic values of stocks with low book-to-market ratios because these stocks show higher growth chances and accordingly higher up-to-judgement information. Under these curcustances, investors are more likely to commit psychological mistakes of overconfidence and self-attribution (Chui et al., 2003). Accordingly, my first hypothesis is that low book-to-market stocks will show higher Taiwanese momentum if DHS model is capable of explaining the seasonal momentum. Secondly, given the assumption of fixed budgets of information costs, investors tend to spend less money on collecting information of small firms due to a smaller proportion of aggregate investment in these firms. Consequently, HS suggest that small firms have a better chance to yield higher momentum profits than large firms due to slower speed of spreading private information across investors. The phenomenon of small firms with higher momentum returns has been affirmed in the U.S. stock market by Hong, Lim, and Stein (2000). As a result, my second hypothesis is that small firms will generate higher seasonal momentum when HS model can explain the seasonal momentum.

This study finds that, inconsistent with both of the above hypotheses, nor with the strong U.S. evidence, the seasonal price continuation in Taiwan is not stronger among low book-to-market stocks, nor among small stocks. As such, this research contributes to the momentum literature by sheding further light to sources of price continuation. Moreover, an implication arises that although existence of price continuation may be a global phenomenon, the underlying sources might be market specific.

The rest of this paper is structured as follows. The following section present data and methodology. Section 4 documents empirical results. Finally, section 5 offers concluding remarks.

\section{Data and Methodology}

To investigate the Taiwanese equity market, I use the exact sample in $\mathrm{Fu}$ and Wood (2010), following the methodology in Chui, et al. (2003) for eight Asian countries. At each portfolio formation date, i.e., the end of each month, for either book-to-market ratios or market capitalisation, I use the division of 30\% (bottom), $40 \%$ (medium), and $30 \%$ (top) to categorise stocks into three subgroups and estimate characteristic-conditioned momentum returns for each subgroup. With respect to estimation of book-to-market ratios, I use book value and market capitalisation at the end of year $t-1$ for holding period of June in year $t$ to May in year $t+1$. It is worth noting that the sample here is smaller than that used in Fu and Wood (2010) in terms of both the number of firms and the time horizon involved, due to two reasons. Firstly, as many delisted stocks do not have full range of available data for early years, especially book values, unavoidably they are dropped out from those periods. Secondly, some early periods are truncated due to not enough firms to form nine portfolios (i.e., loser, medium, and winner portfolios for each of the three subgroups). 


\section{Empirical Results}

\subsection{Momentum Returns Conditional on Book-to-Market Ratio}

Table 1 reports momentum profits for low, medium, and high book-to-market groups respectively, as well as the difference in returns between low and high book-to-market stocks. Panel B shows that low book-to-market ratio stocks weakly under-perform high counterparts in terms of momentum returns for holding periods of April-to-August. In contrast, momentum profits for all months in Panel A present weak evidence of out-performance of stocks with low book-to-market ratios, consistent with the weak results of Chui et al. (2003) for Taiwan but weaker than the strong findings of Daniel and Titman (1999) for U.S. Moreover, the findings hold in most sub-period analysis. In sum, obviously low-BM stocks do not create stronger momentum as expected, resulting in a failure of prediction by DHS.

Table 1. Profitability of momentum strategeies conditional on book-tomarket ratio

\begin{tabular}{ccccc}
\hline & Low & Medium & High & L - H \\
\hline Panel A: All Months & & & & \\
\hline Aug. 1982 - Jun. 2003 & -0.10 & -0.41 & -0.40 & 0.29 \\
(the whole sample period) & $(-0.34)$ & $(-1.23)$ & $(-0.99)$ & $(0.87)$ \\
\hline Aug. 1982 - May. 1987 & 0.31 & -0.10 & 0.17 & 0.14 \\
(the pre-liberalization period) & $(0.51)$ & $(-0.19)$ & $(0.27)$ & $(0.25)$ \\
\hline Jun. 1987 - Jun. 1997 & 0.00 & -0.69 & -0.42 & 0.41 \\
(the pre-crisis period) & $(-0.01)$ & $(-1.52)$ & $(-0.85)$ & $(0.92)$ \\
\hline Jul. 1997 - Jun. 2003 & -0.62 & -0.15 & -0.81 & 0.19 \\
(the post-crisis period) & $(-0.93)$ & $(-0.19)$ & $(-0.80)$ & $(0.24)$ \\
\hline Panel B: April-to-August & & & & \\
\hline Aug. 1982 - Jun. 2003 & 1.16 & 1.10 & 1.39 & -0.23 \\
(the whole sample period) & $(2.68)$ & $(2.52)$ & $(3.04)$ & $(-0.51)$ \\
\hline Aug. 1982 - May. 1987 & 1.54 & 1.23 & 2.42 & -0.88 \\
(the pre-liberalization period) & $(1.45)$ & $(1.81)$ & $(2.90)$ & $(-1.08)$ \\
\hline Jun. 1987 - Jun. 1997 & 0.69 & 0.35 & 0.67 & 0.02 \\
(the pre-crisis period) & $(1.17)$ & $(0.52)$ & $(1.08)$ & $(0.03)$ \\
\hline Jul. 1997 - Jun. 2003 & 1.72 & 2.41 & 1.91 & -0.18 \\
(the post-crisis period) & $(2.25)$ & $(2.94)$ & $(1.89)$ & $(-0.22)$ \\
\hline
\end{tabular}

The $t$ statistics are in parentheses.

\subsection{Momentum Returns Conditional on Size}

Table 2 reveals a consistency of small firms yielding higher momentum profits than large firms for all months as well as for months of April-to-August during all sample periods with the exception of the post-crisis period. Nevertheless, the statistic significane is poor, reminsent weak evidence in Taiwane shown by Chui et al. (2003). Hence, evidence does not confirm significant U.S. results (Hong, Lim, and Stein, 2000), nor the forecasts by HS. 
Table 2. Profitability of momentum strategeies conditional on size

\begin{tabular}{ccccc}
\hline & Small & Medium & Large & S - L \\
\hline Panel A: All Months & & & & \\
\hline $\begin{array}{c}\text { Oct. 1978 - Jun. 2003 } \\
\text { (the whole sample period) }\end{array}$ & 0.22 & -0.16 & -0.10 & 0.32 \\
\hline Oct. 1978 - May. 1987 & 0.37 & 0.18 & -0.23 & 0.60 \\
(the pre-liberalization period) & $(0.90)$ & $(0.49)$ & $(-0.79)$ & $(1.28)$ \\
\hline Jun. 1987 - Jun. 1997 & 0.47 & -0.37 & -0.23 & 0.70 \\
(the pre-crisis period) & $(1.27)$ & $(-1.17)$ & $(-0.63)$ & $(1.56)$ \\
\hline Jul. 1997 - Jun. 2003 & -0.46 & -0.27 & 0.33 & -0.79 \\
(the post-crisis period) & $(-0.56)$ & $(-0.39)$ & $(0.43)$ & $(-1.02)$ \\
\hline Panel B: April-to-August & & & & \\
\hline Oct. 1978 - Jun. 2003 & 1.30 & 1.04 & 0.84 & 0.46 \\
(the whole sample period) & $(3.22)$ & $(3.42)$ & $(2.56)$ & $(0.99)$ \\
\hline Oct. 1978 - May. 1987 & 1.43 & 1.57 & 0.30 & 1.13 \\
(the pre-liberalization period) & $(1.95)$ & $(2.96)$ & $(0.76)$ & $(1.31)$ \\
\hline Jun. 1987 - Jun. 1997 & 1.03 & 0.18 & 0.54 & 0.50 \\
(the pre-crisis period) & $(1.70)$ & $(0.38)$ & $(1.02)$ & $(0.77)$ \\
\hline Jul. 1997 - Jun. 2003 & 1.60 & 1.87 & 2.25 & -0.64 \\
(the post-crisis period) & $(2.01)$ & $(3.20)$ & $(2.69)$ & $(-0.65)$ \\
\hline
\end{tabular}

The $t$ statistics are in parentheses.

\section{Conclusions}

The overconfidence and self-attribution model developed by DHS forecasts a stronger price continuation for low book-to-market stocks. Besides, HS's sluggish information spreading model predicts a higher price continuation for small firms. This study provides evidence that neither predictions can hold in the Taiwanese stock market. The Taiwanese evidence is quite different from the strong confirmation of US evidence, implying that existence of price continuation may a global phenomenon, yet the underlying sources might be market specific.

\section{References}

Carhart, M. (1997). On the persistence of mutual fund performance. Journal of Finance, 52, 57-82. 10.1111/j.1540-6261.1997.tb03808.x

Chan, K., Hameed, A., \& Tong, W. (2000). Profitability of momentum strategies in the international equity markets. Journal of Financial and Quantitative Analysis, 35, 153-172. http://dx.doi.org/10.2469/dig.v31.n1.815

Chen, A. (2000). Momentum does not matter consistently: The evidence from Taiwan stock return. Unpublished working paper. National Sun Yat-sen University. Taiwan.

Chui, A., Titman, S., \& Wei, J. (2003). Momentum, legal systems and ownership structure: an analysis of Asian stock markets. Unpublished working paper. University of Texas at Austin.

Daniel, K., Hirshleifer, D., \& Subrahmanyam, A. (1998). Investor psychology and security market under-and overreactions. Journal of Finance, 53, 1839-1886. http://dx.doi.org/10.1111/0022-1082.00077

Fama, F., \& French, K. (1993). Common risk factors in the returns on stocks and bonds. Journal of Financial Economics, 33, 3-56. http://dx.doi.org/10.1016/0304-405X(93)90023-5

Fu, Hsiao-Peng, \& Andrew, W. (2010). Momentum Profits in Taiwan: Seasonality Matters! Applied Economics Letters, 17, 1247-1253. http://dx.doi.org/10.1080/00036840902917589 
Griffin, J., Ji, X., \& Martin, S. (2005). Global momentum strategies: A portfolio perspective. Journal of Portfolio Management (winter), 23-29. http://dx.doi.org/10.3905/jpm.2005.470576

Grundy, B., \& Martin, J. (2001). Understanding the nature of the risks and the source of the rewards to momentum investing. Review of Financial Studies, 14, 29-78. http://dx.doi.org/10.1093/rfs/14.1.29

Hameed, A., \& Yuanto, K. (2002). Momentum strategies: evidence from the pacific basin stock markets. Journal of Financial Research, 25, 387-397. http://dx.doi.org/10.1111/1475-6803.00025

Hong, H., \& Stein, J. C. (1999). A unified theory of underreaction, momentum trading, and overreaction in asset markets. Journal of Finance, 54, 2143-2184. http://dx.doi.org/10.1111/0022-1082.00184

Hong, H., Lim, T., \& Stein, J. (2000). Bad news travels slowly: size, analyst coverage and the profitability of momentum strategies. Journal of Finance, 55, 265-295. http://dx.doi.org/10.1111/0022-1082.00206

Kang, J., Liu, M., \& Ni, S. (2002). Contrarian and momentum strategies in the China stock market: 1993-2000. Pacific-Basin Finance Journal, 10, 243-265. http://dx.doi.org/10.1016/S0927-538X(02)00046-X

Liu, W., Strong, N., \& Xu, X. (1999). The profitability of momentum investing. Journal of Business Finance and Accounting, 26, 1043-1089. http://dx.doi.org/10.1111/1468-5957.00286

Rouwenhorst, K. (1998). International momentum studies. Journal of Finance, 53, 267-284.

Rouwenhorst, K. (1999). Local return factors and turnover in emerging stock markets. Journal of Finance, 54, 1439-1464. http://dx.doi.org/10.1111/0022-1082.00151

Schiereck, D., De Bondt, W., \& Weber, M. (1999). Contrarian and momentum strategies in Germany. Financial Analyst Journal, 55, 104-116. http://dx.doi.org/10.2469/faj.v55.n6.2317 